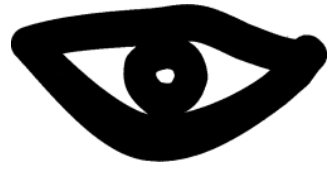

\title{
A docência em EAD e o papel do e-tutor
}

\author{
Ana Perpétua Ellery Corrêa*, Bento Duarte da Silva** \\ * Doutoranda em Ciências da Educação, Universidade do Minho, Portugal, \\ **Professor Catedrático do Instituto de Educação, Universidade do Minho, Portugal
}

\begin{abstract}
Resumo
A educação a distância (EAD) tem ampliado sua participação no cenário mundial por estar sintonizada ao ritmo e dinâmica do mundo global, fazendo com que o espaço de atuação do e-tutor torne-se ainda mais importante. O presente trabalho faz parte da Tese de Doutoramento em Ciências da Educação, especialidade em Tecnologia Educativa, pela Universidade do Minho e tem como propósito apresentar as estratégias de investigação e as bases de reflexão norteadoras do estudo sobre a função pedagógica do e-tutor, valorizando o olhar que este tem sobre si mesmo enquanto educador e promotor da aprendizagem significativa e emancipatória, trazendo como campo de investigação as Instituições de Ensino Superior (IES) vinculadas ao Sistema Universidade Aberta do Brasil (UAB) no Estado do Ceará.
\end{abstract}

Palavras-chave: educação a distância; educação superior; e-tutor; comunicação online.

\begin{abstract}
:
The distance education (EAD) has increased its share in the world scenario for being connected with the rhythm and dynamics of the global world, enabling the e-tutor to have their performance even more important. This work is part of the $\mathrm{PhD}$ thesis in Educational Sciences, specialization in Educational Technology from the Universidade do Minho and aims to present the research strategies and the reflecting bases that guide the study on the e-tutor's pedagogical function, valuing the look that they have on themselves as an educator and promoter of meaningful and emancipatory learning, bringing as research field the Higher Education Institutions linked to the Sistema Universidade Aberta do Brasil (UAB) in the State of Ceará-Brazil.
\end{abstract}

Keywords: distance education; higher education; e-tutor; online communication.

\section{Contextualização}

Na medida em que cresce a oferta de cursos na modalidade de EAD, amplia-se a necessidade da compreensão das tendências tecnológicas e as possibilidades comunicativas que regem as relações em sociedade, de forma que estas caminhem em um mesmo sentido e direção, tornando os espaços e os diálogos online mais contextualizados, atrativos e facilmente assimiláveis por um universo ampliado de indivíduos.

A oferta de cursos a distância com o uso das tecnologias digitais vem se afirmando no cenário educacional mundial, abrangendo diversas áreas e níveis, estando presente no setor público e privado. Resultados do Censo da Educação Superior (2012) para o Brasil demonstram que essa modalidade representa participação superior a 15\% na matrícula de graduação, somando mais de 1,1 milhão de alunos matriculados naquele país. Ainda segundo este documento, no período entre 2011/2012 as matrículas cresceram 3,1\% nos cursos presenciais e 12,2\% nos cursos a distância.

Essa mudança de paradigmas demonstra que a sociedade atual está caminhando para uma adesão crescente à EAD, que flexibiliza a oportunidade de atração e retenção de pessoas que melhor se adequam a esse formato instrucional e aqueles que estavam afastados do sistema educacional por razões diversas.

Somado a essa conjuntura, a sociedade tem se voltado para a compreensão de que a aprendizagem não é algo estanque, determinado a acontecer em um momento específico e com uma configuração padronizada e que, muito pelo contrário, a educação dos tempos atuais precisa ser constantemente revisada e resignificada tendo em conta que ela está disponível para todos a todo momento e lugar, desde que encontre condições tecnológicas e pedagógicas para se fazer presente.

Esse contexto de renovação emergente requer uma atualização recorrente dos métodos didáticotecnológicos na mesma medida e intensidade que exige uma atitude proativa pelo e-tutor, que tem que estar receptivo a mudanças para que seu papel não se torne desfasado e dissociado das reais necessidades do mercado educacional em seus variados tons e matizes.

A e-tutoria envolve situações didáticas complexas que incide desde a adaptação a padrões de linguagens especificas para essa modalidade, sensibilidade para lidar com o aluno virtualmente, capacidade de motivar e articular os saberes a partir de práticas pedagógicas que melhor se ajustem às formas de apresentação de conteúdos online aproveitando as funcionalidades disponibilizadas por plataformas de comunicação das mais variadas; habilidade para a navegação e conhecimento do ambiente virtual; além da abertura para inovar a partir das experiências proporcionadas por cada realidade educacional e suas especificidades.

Torna-se, portanto, urgente e necessário compreender os elementos motivacionais e as diversas faces desse e-tutor em sua praxis, observando e refletindo sobre os papéis que este desempenha e quais as competências, habilidades e atitudes requeridas para o alcance de resultados que atendam aos múltiplos aspectos que compõem essa função.

Para responder aos impasses conceituais que permeiam o tema é preciso repensar as relações e o modus operandi com que se desenvolve a aprendizagem nesse novo meio e conjuntura sócio-histórica em que, mais do que transposição de modelos, exige um pensamento não tendencial, onde a influência da educação presencial tradicional não seja a referência principal para os processos didáticos adotados na educação a distância.

Neste sentido, tendo como foco de análise as Instituições de Ensino Superior (IES) públicas que integram o Sistema Universidade Aberta do Brasil 
(UAB) no Estado do Ceará, o estudo doutoral, uma vez finalizado, pretende responder aos seguintes questionamentos:

- Qual a delimitação existente entre a função docente realizada pelo professor e pelo e-tutor, tendo em vista que ambos desempenham papel de educadores?

- Em que medida esses papéis podem se tornar substitutos, em que se assemelham e diferem, e até que ponto se distanciam, se aproximam ou se complementam?

- $\quad$ O que torna um profissional habilitado a exercer a função de tutoria a distância?

- Qual a identidade profissional que caracteriza um e-tutor? Quais as competências, habilidades e atitudes requeridas para o perfil e identidade do tutor a distância?

- Existe um perfil único de e-tutor ou ele se estabelece orientado pelas estratégias instrucionais de um curso, programa ou sistema?

- O que motiva o tutor e quais as estratégias de aprendizagens que ele recorre para dinamizar e inovar em sala de aula online?

- Quais os maiores desafios do e-tutor e quais os mecanismos de superação por ele utilizados?

\section{Motivações do estudo}

Entende-se que para o e-tutor atender às expectativas educacionais orientadas ao exercício da sua função, independentemente da situação didática adotada, é importante que a abrangência da sua atuação seja claramente compreendida, o que nem sempre acontece.

Analisando a acepção da palavra tutor e os avanços nas discussões relativas aos papéis e as novas relações que emergem no contexto da EAD, verifica-se que as especificidades que identificam a atuação do educador que exerce a função de tutoria a distância ainda se encontram pouco estabelecidas em termos de competências, habilidades e atitudes requeridas para a realização do que Kenski (2010) denomina de "trocas pedagógicas online”.

A ausência de um marco regulatório mais abrangente no que tange ao perfil e atribuições inerentes à função tutorial fragiliza a atividade que passa a ser regida pela concepção pedagógica de cada Curso, Programa ou Sistema e que, por vezes, não está alinhada a outros cursos realizados também na modalidade a distância. Essas diferenciações de estruturas de cursos e de diretrizes de gestão educacional dificultam o reconhecimento de competências pedagógicas que atendam à dimensão tutorial como um todo.

O estudo ora proposto encontra motivação em captar a percepção do e-tutor que atua no contexto do Ensino Superior sobre si mesmo no desempenho de sua atividade no processo de construção da aprendizagem. Partindo dessa investigação para ampliar reflexões em torno da construção da identidade do tutor a distância para além do universo investigado, que incide nas IES públicas do Estado do Ceará.

\section{E-tutoria no Ensino Superior}

As IES se caracterizam como o lócus do ensino, da investigação e da produção de conhecimento, onde as dimensões técnico-científicas, a ética, a responsabilidade social e o pensamento crítico encontram espaço para se desenvolverem, a partir da ação docente orientada para a formação de indivíduos em níveis pessoal, profissional e humano, a serviço de uma sociedade mais justa e preparada para os desafios que se colocam.

Para Edgar Morin (2000, p. 15), “a Universidade conserva, memoriza, integra e ritualiza uma herança cultural de saberes, ideias e valores (...) por isso, a universidade é conservadora, regeneradora e geradora”.

À IES, cabe, portanto, a formação específica mas também, e sobretudo, o papel de despertar o interesse e a reflexão da comunidade acadêmica e da sociedade para uma visão holística e contextualizada do mundo, permeada por aspectos que contemplem a inter e a transdisciplinaridade, privilegiando a formação de valores e o fortalecimento da cidadania, quer seja nas áreas humanas ou nas áreas técnicas.

Nas IES, no contexto da EAD, alunos, professores, tutores, pesquisadores, designers instrucionais e demais atores integram-se na perspectiva de conceber, promover transições didáticas e compartilhar conhecimentos. O desafio consiste em potencializar recursos e capital humano que melhor se ajustem às demandas educacionais cada dia mais sofisticadas e desafiadoras.

Apontando para essa direção, ressalta-se os resultados obtidos em uma investigação sobre as competências em Tecnologias Digitais de Informação e Comunicação TDIC dos docentes do ensino superior, em Portugal e no Brasil que revela "que a maioria dos professores apresenta um bom desempenho com as TDIC no seu cotidiano (utilização pessoal), mas que ainda se encontram num processo de desenvolvimento quanto às suas competências de desempenho na gestão pedagógica” (Silva, et. al., 2014, s/p).

Dada essa conjuntura, Maggio (2001) defende que o papel do e-tutor é uma das questões mais debatidas em EAD. Para a autora há uma necessidade de se pensar sobre essa função e a proposição de uma ressignificação do nome tutor.

Dias (2008) resgata a concepção do e-moderador, que atua em ambientes de ensino e aprendizagem virtuais como agentes de participação e interação social, de construção de significados e conhecimento coletivo para além das funções de informar, transmitir conteúdos e organizar as comunidades de aprendizagem em rede.

Ainda no conceito de e-moderador, Salmon (2000:25) ressalta que as atividades realizadas em comunidades virtuais constituem-se de níveis/fases de progressão, partindo do acesso e motivação, caminhando para a socialização online, troca de informação, construção do conhecimento, seguida de desenvolvimento pleno que culmina na aprendizagem.

Apesar de, aparentemente, ser muito esclarecedora a função do e-tutor se pauta em situações pouco claras, na 
medida em que a descrição da sua atuação encontra-se precedidas dos verbos "acompanhar", "apoiar", "mediar" e "colaborar" que necessitam uma maior explicitação em termos de como e em que medida.

A imprecisão do grau de envolvimento em cada uma dessas etapas acrescidas à prerrogativa de que ficar a cargo de cada instituição de ensino determinar "as atividades a serem desenvolvidas para a execução dos Projetos Pedagógicos, de acordo com as especificidades das áreas e dos cursos", conforme expresso anteriormente, dificulta uma compreensão clara dos limites e da abrangência real da função do tutor a distância.

Sá (1998) se reporta, em relação ao tutor, como sendo o orientador que atua na aprendizagem do aluno que, solitário e isolado, frequentemente necessita do docente ou de um orientador para indicar caminhos que facilitem sua aprendizagem.

Em outras palavras, o tutor a distância assumiria o papel de monitor, tendo em vista que este constantemente tem que pactuar com a automotivação de pessoas associada ao seu potencial e envolve aspectos como direcionamento, aconselhamento e liderança para aprimoramento de competências com foco em resultados.

Essas novas relações de trocas e compartilhamento no contexto educacional suscitam a necessidade de um modelo que os represente, o que é esperado do tutor a distância em termos de currículo, gestão da sala de aula e dos saberes (didática) e mecanismos de acompanhamento e avaliação que se coadunem com essa estrutura mais interativa, partilhada e colaborativa de ensino.

Adaptar essa prática pedagógica à infraestrutura física ao aporte tecnológico e humano, ao modelo instrucional e de comunicação online presentes em cada realidade educativa representa um desafio adicional à atividade tutorial nesta modalidade de ensino. Para tanto, o exercício da apropriação dos componentes eletrónicos articulados ao uso da linguagem didática que seja mais adequada às especificidades inerentes ao universo virtual torna-se necessário para aqueles que ensejam fazer uso desses recursos com vista a abertura de novos caminhos que venham contribuir para o estabelecimento de mediações e interações colaborativas voltadas para o desenvolvimento de saberes.

Esse tutor, tão rico em suas potencialidades, se vê podado por limites reais ou imaginários provocados por sua crise de identidade docente, com suas dúvidas, sua incapacidade de saber até onde ir, como se posicionar e como exercer, de forma legítima, sua função, direcionando suas práticas para obtenção de melhores resultados.

No embasamento teórico do presente trabalho serão verificados os avanços das teorias na área de Educação e, mais especificamente, em EAD, no contexto do Ensino Superior, com foco na abordagem sobre o papel do tutor em cursos online.

Para delimitação do objeto, foram definidas como categorias principais: educação a distância, docência, e-tutoria e e-learning.

\section{Metodologia de investigação}

A metodologia de investigação está pautada em um estudo de natureza exploratória, que irá utilizar como instrumento de investigação a análise documental a partir da observação de editais/chamadas públicas de seleção de tutores a distância, da legislação vigente, pareceres, resoluções, censos, projetos pedagógicos institucionais, livros, repositórios de teses, anais de eventos científicos, artigos e dissertações, além de referências bibliográficas de relevância na área.

A abordagem metodológica a ser seguida tem como premissa fornecer elementos de análise estatística que permitam validar os resultados obtidos, tendo em conta uma articulação com o aprofundamento da análise dos aspectos subjetivos captados nos distintos momentos da pesquisa. Desta forma pretende-se captar, de forma sistêmica, como se dá o processo de aprendizagem a partir das vivências e situações de aprendizagem gerenciadas pelo e-tutor no ambiente virtual, analisando o tipo de formação requerida para a atuação deste profissional para o alcance de melhores resultados de desempenho docente.

A estratégia adotada contará com a aplicação de questionários semiestruturadas envolvendo o universo respondente dos tutores a distância e os coordenadores pedagógicos de cada instituição. Esta etapa é precedida de 3 níveis de validações: (i) falada, realizadas com uma tutora a distância da UAB Ceará: (ii) validação de conteúdo com 6 especialistas em EAD e (iii) pré-testagem com 4 tutores que não fazem parte do universo pesquisado.

Os questionários a serem aplicados com esse público-alvo do estudo abrangem grupos de perguntas organizadas em 4 dimensões que se reportam, respectivamente, ao perfil docente do e-tutor, aos aspectos motivacionais do e-tutor, à avaliação, da práticas pedagógicas e à percepção dos e-tutores em relação à UAB.

Em seguida serão realizados momentos de aprofundamento do tema a partir da constituição de grupo focal por 10 e-tutores articulados em conjunto com uma formação no tema e posterior análise dos avanços obtidos a partir das discussões.

\section{Resultados e situação atual do estudo}

O estudo encontra-se na segunda etapa de validação. A primeira etapa foi avançada com diálogo livre e contou com o registro das observações.

A segunda etapa foi desenvolvida a partir de um convite a especialistas em que eram descritos os objetivos da investigação e o objetivo de suas participações. Como anexo seguia o questionário e um roteiro com um quadro com quatro colunas contendo: (i) os setores do questionário; (ii) se concorda com as questões (sim/não e comentários); (ii) o que mudaria e (iv) o que acrescentaria.

Como resultado desse processo foi sugerida uma análise pormenorizada dos editais de seleção da UAB, a começar pelo Estado do Ceará, no que se refere à participação do tutor a distância no contexto das suas atribuições (que podem estar associadas a um curso, uma 
disciplina ou um bloco de disciplinas) e perfil requerido, estabelecendo um comparativo e pontuando as discordâncias verificadas.

Outras questões como uma reflexão sobre tendências de reformulações no papel do tutor a distância em uma visão prospectiva (onde esse passaria a assumir funções que atualmente são de responsabilidade do professor regente e/ou do tutor presencial) e o papel da gestão e das relações entre os agentes educacionais no sucesso do desempenho educacional foram propostas como sendo interessantes para aprofundamento no estudo.

Aspectos como razões da evasão, adequação das ferramentas tecnológicas ao planejamento didático da disciplina/curso, relação entre a quantidade de alunos para cada tutor a distância, grau de autonomia dada ao e-tutor e adequação da carga horária para o desenvolvimento de suas atividades, envolvimento do e-tutor na coprodução de conteúdos, bem como o formato e abrangência da formação para atuar em EAD foram pontuados, assim como a necessidade do desenvolvimento de pertença nos tutores a distância, adequação de remuneração de forma a torná-la compatível com os demais atores que atuam do ensino superior e o reconhecimento destes como docentes.

Em termos de formulação das perguntas foi sugerida uma adequação dos parâmetros àqueles utilizados em documentos oficiais, de forma a facilitar a comunicação e o entendimento por parte dos e-tutores respondentes.

A etapa seguinte estará voltada para a de aplicação dos questionários, antecedida pela pretestagem e posterior análise dos resultados.

Espera-se que o presente estudo contribua para ampliar as discussões relativas ao espaço do e-tutor no contexto educacional, destacando a sua importância com ênfase no contexto do Ensino Superior e a expressão que esta atividade tem alcançado nos dias atuais, além de dar relevo e visibilidade às expectativas, motivações e desafios que estes se deparam no cotidiano.

\section{Referencias}

INEP/MEC. Resultados do Censo da Educação Superior 2012. (2012). Inep/MEC. Disponível : http://download.inep.gov.br/educacao basica/cens o_escolar/resumos tecnicos/apresentacao_coletiva censo superior 2012.pdf

Kenski, V.M. (2010). Avaliação e acompanhamento da aprendizagem em ambientes virtuais, a distância. (pp. 59-68). In: MILL, D., PIMENTEL,N (eds). Educação a Distância: desafios contemporâneos. São Carlos: EdUFSCar.

Maggio, M. (2001). O tutor na educação a distância. In: LITWIN. E. (org.) Educação a distancia: temas para o debate de uma nova agenda educativa. (pp. 93-110). Porto Alegre: ARTMED.

Morin, E. (2000). Complexidade $e$ transdisciplinaridade: a reforma da universidade $e$ do ensino fundamental. (2000). Natal: EDUFRN.

Sá I.M.A. (1998). A Educação a Distância: processo contínuo de inclusão social. Fortaleza: CEC.

Salmon, G. (2000). E-Moderating, The Key to Teaching and Learning Online. London, UK: Kogan Page.
Silva, B., Araújo, A. M., Vendramini, C. M., Martins, R. X., Piovezan, N. M., Prates, E., Dias, A. S., Almeida, L. S., Rodrigues, M. C. \& Joly, A. (2014). Aplicação e uso de Tecnologias digitais pelos professores do ensino superior no Brasil e Portugal. Educação, Formação \& Tecnologias, (pp. 3-18). Disponível: http://eft.educom.pt/index.php/eft/article /view/424/195.

\section{Agradecimento}

Agradecimento à FCT pelo apoio concedido no âmbito da Bolsa de Investigação contemplada pelo Programa de Doutoramento FCT - Aprendizagem Enriquecida com Tecnologia e Desafios Societais. 